\title{
A STUDY OF LATERAL INHOMOGENEITIES IN THE UPPER MANTLE BY MULTIPLE SCS TRAVEL-TIME RESIDUALS
}

\author{
Emile A. Okal and Don L. Anderson
}

Seismological Laboratory, California Institute of Technology, Pasadena California 91125

Abstract. An analysis of records of multiply reflected ScS phases from ten deep-focus earthquakes yields near-vertical one-way travel-time residuals varying from +5.0 to $-3.5 \mathrm{~s}$. Continental and oceanic residuals overlap and both indicate large lateral variations. Similar values are found for the older oceanic basins and for continental shields. Most, if not a1l, of the variations can be attributed to differences in the lithosphere and asthenosphere. The mantle under Hawaii, Iceland and Trindade (South Atlantic) Islands is anomalously slow, all being postulated hotspots. In the case of Trindade, petrological data is consistent with a pronounced low-velocity zone and large $\mathrm{S}$ delays. Some recent studies assumed that stations on oceanic islands were representative of the ocean as a whole and it has been suggested that continentocean differences extend deeper than $400 \mathrm{~km}$. The present results indicate that oceanic islands are anomalous, and that differences between oceans and continents need not extend below $200 \mathrm{~km}$. This does not rule out the existence of deep lateral inhomogeneities, but only the proposal that continents, in general, are faster than oceans to depths greater than $400 \mathrm{~km}$.

One of the basic premises of plate tectonic theory is that relatively thin plates (50-75 $\mathrm{km}$ under oceans and 150-250 km under continents) are moving about over a partially molten asthenosphere [Anderson, 1962; Anderson \& Sammis, 1970]. Because of the distribution of seismic stations and earthquakes, most studies of the structure of the Earth have a strong continental bias. Free oscillation results [Jordan \& Anderson, 1974; Gilbert \& Dziewonski, 1975; Anderson et al. , 1975] indicate that the average Earth has slower seismic velocities than determined from most body-wave solutions. Studies of greatcircle surface wave dispersion curves [Anderson \& Toksöz, 1963] indicate the same. Most of the information regarding oceanic upper mantle structure, to depths greater than $100 \mathrm{~km}$, has come from surface wave studies. They indicate that the oceanic lithosphere is faster than the continental one, but the oceanic asthenosphere is slower, being probably both slower and thicker. Because of the limited depth resolution of surface waves, and lateral variations in the oceans, it is important to test the basic plate tectonic premise by independent means.

Sipkin \& Jordan [1975] studied lateral inhomogeneities of the upper mantle by use of the phase ScS for a number of deep events. They found a difference of $5 \mathrm{sec}$ between oceans (slow) and Copyright 1974 by the American Geophysical Union. continents (fast), and argued that continental and oceanic mantle must differ to at least 400 $\mathrm{km}$ and possibly as deep as $600 \mathrm{~km}$. However, their oceanic data rests entirely on the use of only 4 stations, which they presume to represent normal ocean: KIP, Hawai1; RAR, Cook Islands; AFI, Samoa, and BEC, Bermuda. All of these are on vo1canic islands whose activity is in no case older than $30 \mathrm{~m} . \mathrm{y}$. It is questionable, indeed, whether any island station can be taken as standing on typical oceanic 1ithosphere. In order to investigate travel-time anomalies in areas where no stations are available, we studied travel-time residuals for multiply-reflected ScS waves. The surface-reflection points of many of these phases are at places which cannot be studied by use of direct phases, such as $S$ or ScS.

The residual $\delta$ (observed minus JeffreysBullen (JB) times), say for $\mathrm{ScS}_{2}$, may be written:

$$
\delta_{\mathrm{ScS}_{2}}=\mathrm{A}_{\text {epic }}+\mathrm{A}_{\text {refl }}+\mathrm{A}_{\text {rec }} .
$$

A epic, the anomaly at the epicenter, is due to possible mislocation, uncertainty in the origin time, and structure around the epicenter; $A_{\text {refl }}$ is the contribution at the surface reflection point and $A_{\text {rec }}$ the contribution at the recelver, due to local structure under the station. Clearly because of the quasi-vertical incidence of any ScS path, the anomalies Aepic and $A_{\text {rec }}$ are approximately the same for $\mathrm{ScS}$ or any $\mathrm{ScS}_{\mathbf{n}}$. Therefore, the difference in time residuals $\delta_{\mathrm{ScS}_{2}}-\delta_{\mathrm{ScS}}$ clearly represents $\mathrm{A}_{\text {ref1 }}$, which, in turn, because of the steep incidence of any $\mathrm{ScS}_{\mathrm{n}}$, is approximately equal to twice the oneway anomaly to a vertical $\mathrm{s}$, due to upper mantle structure under the reflection point. In the case of a higher order $\mathrm{ScS}_{n}$, such anomalies at the various reflections would clearly add up to :

$$
[1 / 2] \cdot\left[(o-c) \operatorname{ScS}_{n}-(o-c) S_{S c S}\right] \text {. }
$$

We used long-period records from ten deepfocus events (see Table 1) at 49 WWSSN stations. A total of $77 \mathrm{ScS}_{2}, 15 \mathrm{ScS}_{3}$ and $2 \mathrm{ScS}_{4}$ were used. Records were digitized and cross-correlated to obtain ${ }^{\circ} \mathrm{ScS}_{2}-{ }^{\circ} \mathrm{ScS}$. At distances larger than $70^{\circ}$, the phase $S$ was used rather than ScS, and the time anomaly obtained, therefore, was $(o-c)_{\mathrm{ScS}_{2}}-(\mathrm{o}-\mathrm{c})_{\mathrm{S}}$. Computed values were corrected for ellipticity and for topographical elevation at the surface-reflecting point. We estimate that the resulting values are accurate to \pm 0.5 sec. Additionnally, we calculated a number of cross-correlations between records of the same event at different stations, in order to compare residuals at KIP, POO, AKU and WIN (see Fig.1) with delays on the North American conti- 
Table 1 : Seismic Events used in this Study

\begin{tabular}{|c|c|c|c|c|c|}
\hline No. & Region & Date & Origin Time & Latitude & Longitude \\
\hline $\begin{array}{l}1 . \\
2 . \\
3 . \\
4 . \\
5 . \\
6 . \\
7 . \\
8 . \\
9 . \\
10 .\end{array}$ & $\begin{array}{l}\text { Fiji-Tonga } \\
\text { North Argentina } \\
\text { Fiji-Tonga } \\
\text { North Argentina } \\
\text { Sea of Okhotsk } \\
\text { Sea of Okhotsk } \\
\text { Banda Sea } \\
\text { Peru-Brazil } \\
\text { Banda Sea } \\
\text { Peru-Brazil }\end{array}$ & $\begin{array}{rll}9 & \text { Oct } & 67 \\
8 & \text { Dec } & 62 \\
10 & \text { Feb } & 69 \\
9 & \text { Sep } & 67 \\
29 & \text { Jan } & 71 \\
30 & \text { Aug } & 70 \\
18 & \text { Oct } & 64 \\
15 & \text { Feb } & 67 \\
11 & \text { Feb } & 69 \\
3 & \text { Nov } 65\end{array}$ & $\begin{array}{l}17: 21: 46.2 \\
21: 27: 21.0 \\
22: 58: 03.3 \\
10: 06: 44.5 \\
21: 58: 03.2 \\
17: 46: 08.9 \\
12: 32 ; 24.9 \\
16: 11: 11.8 \\
22: 16: 11.5 \\
01: 39: 03.2\end{array}$ & $\begin{array}{r}21.10 \mathrm{~s} \\
25.78 \mathrm{~S} \\
22.75 \mathrm{~S} \\
27.62 \mathrm{~S} \\
51.69 \mathrm{~N} \\
52.36 \mathrm{~N} \\
7.17 \mathrm{~S} \\
9.05 \mathrm{~S} \\
6.76 \mathrm{~S} \\
9.04 \mathrm{~S}\end{array}$ & $\begin{array}{rl}179.3 & \mathrm{~W} \\
63.13 & \mathrm{~W} \\
178.76 & \mathrm{E} \\
63.15 & \mathrm{~W} \\
150.97 & \mathrm{E} \\
151.64 & \mathrm{E} \\
123.86 & \mathrm{E} \\
71.34 & \mathrm{~W} \\
126.74 & \mathrm{E} \\
71.32 & \mathrm{~W}\end{array}$ \\
\hline
\end{tabular}

nent, as determined by Hales \& Roberts [1970].

Results are shown on Fig.1. The Pacific Ocean exhibits strong lateral variations: values averaging t0.9 sec are found along the line FijiSouthwest U.S., whereas the Northern Pacific averages $-1.2 \mathrm{sec}$. Strong positive anomalies are found in the Artic's Eurasia Basin (+2.3 $\mathrm{sec})$, in the Philippine Sea ( $3 \mathrm{sec})$, in the Tasman Sea $(+3.9 \mathrm{sec})$ and at the Mid-Pacific Mountains $(-5 \mathrm{sec})$. Values at the trenches $(-1.1$ $\pm 0.6 \mathrm{sec}$ at the Alaska trench, $0.4 \pm 2 \mathrm{sec}$ off Guatemala) are largely scattered, the reflection being undoubtedly affected by the descending slab. South America also shows lateral variatlons, and can be separated into two regions: the Andes, where no substantial anomaly is found (relative to JB), and the Brazilian shield, averaging $-2.15 \pm 1 \mathrm{sec}$. An intermediate zone, located along the slopes of the Andes, makes a smooth transition and averages $-1.2 \mathrm{sec}$.
It is not possible to account for these data with Sipkin \& Jordan's [1975] hypothesis of a simple continent vs. ocean difference. Their model of a $5 \mathrm{sec}$. delay of oceanic travel-time would lead to a total delay of $20 \mathrm{sec}$ for $\mathrm{ScS}_{3}$, and $30 \mathrm{sec}$ for $\mathrm{ScS}_{4}$. No such values are obtained in the present study and such a discrepancy between ocean and continent is not revealed by our data. Furthermore, the small anomaly of +1 $\mathrm{sec}$, only $250 \mathrm{~km}$ away from Bermuda, is inconsistent with their assumption that station BEC $(\sim 3.5 \mathrm{sec}$ late) is representative of the mean ocean floor.

On the other hand a good correlation exists between the values of the anomalies and the age of the plate: negative anomalies $1.5 \mathrm{sec}$ are found in the Northcentral Pacific, where the ocean floor is about $100 \mathrm{~m} . \mathrm{y}$. old. On the opposite, the region of the Pacific between 125 and $150^{\circ} \mathrm{W}$ shows positive anomalies of $\sim 1$ sec. Simil-

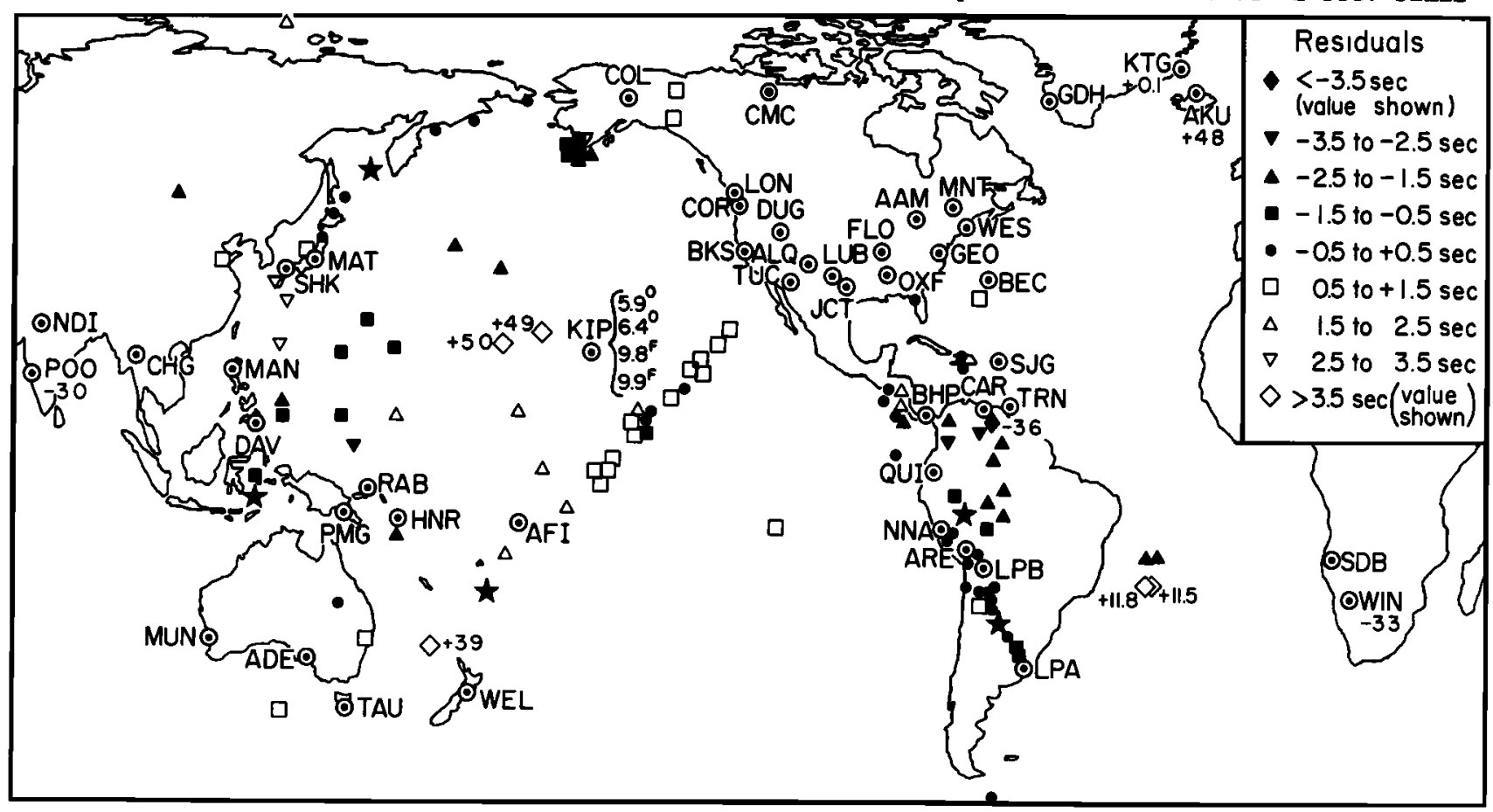

Fig.1: Map of the world showing one-way $S$ anomalies as described in legend. Values of anomalies larger than $3.5 \mathrm{sec}$ in absolute value are shown on map. Stars each identify 2 events. Circled dots are stations with 3-letter code. Numbers adjoining stations are one-way anomalies from direct $s$ or ScS correlations. At KIP, superscripts 0 and $F$ identify values from respectively okhotsk Sea and Fiji. Antartic stations SBA (Scott Base) and SPA (South Pole) used in study, are not shown on map. 
arly, the Brazilian shield exhibits anomalies of -2 to $-3 \mathrm{sec}$; ScS delays at POO, India $(-3 \mathrm{sec})$ and WIN, South Africa $(-3.3 \mathrm{sec})$, both stations on shield, are also similar. Delays in the Brazil Basin $(-2.05 \pm 0.5 \mathrm{sec})$ do not differentlate substantially this old oceanic floor from the adjoining Brazilian shield. The similarity in traveltime between the older parts of the ocean and old continental shield argues against deep structural differences and suggests that both regions have poorly-developed low-velocity zones. It is worthwhile checking this important result with other data. For this purpose, we compute one-way trave1-times above $180 \mathrm{~km}$, for a variety of structures. Leeds et a1. [1974] and Kausel et al. [1974]determined oceanic crustal and upper mantle structure as a function of age from Rayleigh waves crossing the Pacific. They found phase velocity increasing with age and attributed it to thickening of the 1ithosphere at the expense of the asthenosphere. Although their models are not unique, they should yield roughly the right average shear velocity for the upper mantle. They fixed the base of the $1 \mathrm{r}$ model at $180 \mathrm{~km}$ and it is therefore convenient to compare aỵerage velocities above this level. This is done in Table 2 . Residuals in the Pacific vary from $-2.6 \mathrm{sec}$, for $150 \mathrm{~m} . \mathrm{y}$. old crust to $+1.3 \mathrm{sec}$, for young, $\sim 5 \mathrm{~m} . \mathrm{y}$. old crust. A value of $+1.9 \mathrm{sec}$ is extrapolated for the ridge, although this is a minimum value, since the mantle under the ridge is likely to be slower than assumed. An estimate for the midAtlantic ridge is $+3.6 \mathrm{sec}$, obtained by modifyIng a structure proposed by Francis [1969], for the region South of Iceland. Alternate estimates of +2.5 to $5.2 \mathrm{sec}$ are obtained from measured Pdelays at Iceland. These values are roughly consistent with those found in this study for AKU by direct measure of $S$ and $S c S$ delays. A value of $+4.4 \mathrm{sec}$ was recently reported along the midAtlantic ridge by Girardin \& Poupinet [1974]. The value obtained from Leeds et al's structure for $100 \mathrm{~m} . \mathrm{y}$. old 11 thosphere $(-1.6 \mathrm{sec})$ agrees almost exactly with the value $(-1.5 \mathrm{sec})$ found here for the oceanic region of this age in the Northcentral Pacific.
The variation of shear velocity with depth in the published models [Jordan \& Anderson, 1974; Anderson et al., 1975] considered by Sipkin \& Jordan [1975] also gives support to the idea that variations in the $S c S$ residuals are due primarily to variations in the upper mantle. For example, the spread of one-way vertical $S$ tnavel-time for a variety of models, is $2.0 \mathrm{sec}$ to $50 \mathrm{~km}$, increasing to $3.0 \mathrm{sec}$ to $200 \mathrm{~km}$. Differences between models remain between 1.6 to $3.2 \mathrm{sec}$ down to $700 \mathrm{~km}$, indicating that most of the variation is above $200 \mathrm{~km}$. The present conclusions may be compared with those of Tryggvason [1961] who used a particularly favorable geometry of events to study both oceanic and continental structure. He concluded that at a depth less than $400 \mathrm{~km}$, possibly at $140 \mathrm{~km}$, the difference between oceanic and continental structure had disppeared. Our results also compare favorably with those of Hart $\&$ Press [1973] who used $S_{\mathfrak{n}}$ velocities across the Atlantic to investigate the cooling of the lithosphere away from the ridges. They found a large similarity between continents and old oceanic floor.

Finally, strong positive anomalies are found for rays propagating in the top section of proposed mantle hotspots: ScS at KIP, Hawail, is delayed $6 \mathrm{sec}$ from the Sea of Okhotsk, and $9.8 \mathrm{sec}$ from the F1ji-Tonga area. $\mathrm{ScS}_{2}$ recorded at WIN from two deep Peruvian earthquakes of almost identical epicenter both show an anomaly of $+11.5 \mathrm{sec}$ at their reflecting point, located at the island of Trindade. The observed data at KIP suggests that the top part of the upwelling column has to be made of slow material, even if the total vertical travel-time agrees with JB [Best et al., 1974]. This would require a vertical inhomogeneity in the column, with a higher velocity at the bottom, as proposed by Anderson [1975]. In Anderson's model, the top part of a plume is slower than normal mantle, due to increased partial melting, the deeper part being faster, due to chemical differences. Finally, the anisotropy observed at Hawaif could result from the horizontal distance $(300 \mathrm{~km})$ between KIP and the presumed hotspot colum.

Table 2 : JB Residuals for the Upper $180 \mathrm{~km}$ Vertical $\mathrm{S}$ travel-Time in a variety of models.

Mode1 Reference Computed Residual Observed value (this study)

\begin{tabular}{|c|c|c|c|c|}
\hline $\begin{array}{l}\text { LKK } \\
\text { LKK } \\
\text { LKK } \\
\text { LKK }\end{array}$ & $\begin{array}{l}\text { Leeds et a1.[1974], } \\
\text { " } \\
" \\
"\end{array}$ & $\begin{array}{rl}150 & \mathrm{~m} . \mathrm{y} . \\
100 & " \\
70 & " \\
10 & "\end{array}$ & $\begin{array}{r}-2.6 \mathrm{sec} \\
-1.2 \\
0.0 \\
+1.3\end{array}$ & $\left\{+\frac{-1.6}{+0.9}\right.$ at $50 \mathrm{~m} . \mathrm{y}$ \\
\hline CANSD & $\begin{array}{c}\text { Brune and Dorman [19 } \\
\text { (Canadian shield) }\end{array}$ & 963] & -1.3 & -2. (Brazilian shield) \\
\hline $\mathrm{C} 2$ & $\begin{array}{l}\text { Anderson et al. [197 } \\
\text { (Average Earth) }\end{array}$ & 75] & -0.7 & \\
\hline CIT11A & Anderson and Toksoz & [1963] & -0.6 & \\
\hline SHR14 & $\begin{array}{l}\text { Helmberger and Engen } \\
\text { (North America) }\end{array}$ & n $[1974]$ & -0.2 & \\
\hline
\end{tabular}


In the case of Trindade, Oversby [1971] and Baker [1973] have shown that the island is unique among Atlantic islands in its degree of undersaturation, suggesting origin from a hydrous mantle. This is consistent with a greater degree of partial melting and large $S$ delays. The large contrast between $S$ anomalies at Trindade $(+11.5 \mathrm{sec})$ and in the nearby Brazil Basin $(-2$ sec) constrains this partially molten region to a restricted area and strongly advocates for the existence of a hotspot, as proposed by Minster et a1. [1974].

Conclusion. Lateral variations of $\mathrm{S}$ traveltime residuals as reported in this letter occur over distances too short to let them be associated with structures $400 \mathrm{~km}$ or deeper. Rather, they seem to correlate falrly well with the general pattern of plate tectonics. Delays, in general, decrease with the age of the plate and are largest for oceanic islands and recently active continetal areas. The older oceanic lithosphere has residuals similar to continental shields. The residuals are generally consistent with variations in the upper $200 \mathrm{~km}$ found by independent means. The responsible structures should primarily be sought in the lithosphere and asthenosphere. A study of relative attenuation of the seismic phases used in this study, present1y under way, will yleld additional data and will be the subject of a separate paper.

Acknowledgments. This research was supported by the Advanced Research Project Agency of the Department of Defence and was monitored by the Air Force Office of Sciensific Research under contract F44620-72-C-0078. Contribution 2641, Division of Geological and Planetary Sciences, Califonia Institute of Technology.

\section{References}

Anderson, D.L., The Plastic Layer of the Earth's Mantle, Sclentiflc American, July 1962.

Anderson, D.L., Chemical Plumes in the Mantle, Bul1. Geol. Soc. Amer., in press, 1975.

Anderson, D.L., R.S. Hart and T.H.Jordan, An Earth Model Based on Free Oscillations and Body Waves, J. Geophys. Res., In press, 1975.

Anderson, D.L. and C. Sammis, Partial Melting in the Upper Mantle, Phys. Earth Plan. Int., 3 , 4150,1970 .

Anderson, D.L. and M.N.Toksöz, Surface Waves on a Spherical Earth;1. Upper Mantle Structure from Love Waves, J. Geophys. Res. ,68, 3483-3500, 1963.

Baker, P.E., Islands in the South Atlantic, in: The
Oceans Basins and Margins, Vol.1,pp.493-5533, P1enum, New-York, 1973.

Best, W.J., L.R. Johnson and T.V.McEvilly, ScS and the Mantle Beneath Hawaii, E®S Trans. AGU, $55,1147,1974$.

Brune, J.N, and J. Dorman, Seismic Waves and Earth Structure in the Canadian Shield, Bull. Seism. Soc. Amer. , 53,167-210,1963.

Francis, T.J.G., Upper Mantle Structure along the Axis of the Mid-Atlantic Ridge near Iceland, Geophys. J. Roy. Astr, Soe., 17, 507-520,1969.

Gilbert, F. and A.M. Dziewonski, An Application of Normal Mode Theory to the retrieval of Structural Parameters and source mechanisms from Seismic Data, Phil. Trans. Roy. Soc. London, 278A, 187-269,1975.

Girardin, N. and G. Poupinet, Teleseismic S travel-time delays for Mid-Atlantic Ridge Earthquakes, Phys. Earth Plan. Int., 9, 306-313,1974.

Hales, A.L. and J.L. Roberts, The Travel-Times of $S$ and SKS, Bu11. Seism. Soc. Amer. $, 60,461-489$, 1970 .

Hart, R.S. and F. Press, $S_{n}$ velocities and the composition of the lithosphere in the Regionalized Atlantic, J. Geophys. Res. ,78, 407-411, 1973.

Helmberger, D.V. and G.R. Engen, Upper Mantle Shear Structure, J. Geophys. Res., 79,40174028,1974

Jordan, T.H. and D.L. Anderson, Earth Structure from Free Oscillation and Travel-Times, Geoph. J. Roy. Astr. Soc. ,36, 411-459, 1974 .

Kausel, E.G.,A.R. Leeds and I. Knopoff, VariatIons of Rayleigh Wave Phase Velocity across the Pacific Ocean, Science, 186,139-141,1974.

Leeds, A.R., E.G. Kausel and L. Knopoff, Variations of Upper Mantle Structure under the Pacific Ocena, Science, 186, 141-143,1974.

Minster, J.B.,T.H. Jordan, P. Molnar and E. Haines, Numerical Modelling of Instantaneous Plate Tectonics, Geophys. J. Roy. Astr. Soc., 36, 541-576, 1974 .

Oversby, V.M., Lead in Ocean Islands:Faial, Azores and Trindade, Earth P1an. Sci. Lett.,11,401$406,1971$.

Sipkin, S.A. and T.H. Jordan, Lateral Heterogeneity of the Upper Mantle determined from the trave1-t1mes of ScS, J. Geophys. Res., $\underline{80}$, $1474-1484,1975$.

Tryggvason, E., Wave Velocity in the Upper Mantle below the Artic-Atlantic Ocean and Northwest Europe, Annali di Geofisica, 14, 379-392,1961.

(Received July 2, 1975; accepted July 16, 1975.) 